\title{
REPENSAR LA RELACIÓN EDUCATIVA DESDE LA PEDAGOGíA DE LA ALTERIDAD
}

\author{
Rethinking the educational relationship \\ from the pedagogy of alterity
}

\author{
Eduardo S. Vila MERINO \\ Universidad de Málaga. España. \\ eduardo@uma.es \\ bttp://orcid.org/0000-0002-8598-7654
}

Fecha de recepción: 03/03/2019

Fecha de aceptación: 01/05/2019

Fecha de publicación en línea: 08/05/2019

\section{RESUMEN}

Este artículo se plantea realizar un recorrido por cómo se construyen las relaciones educativas desde la perspectiva de la pedagogía de la alteridad. Para ello comienza reflexionando en torno a cómo la relación educativa debe ser un tema central en la teoría de la educación y cuáles pueden ser algunos de sus elementos definitorios más importantes, partiendo del análisis de la bibliografía existente, fundamentalmente en el contexto español. A partir de ahí, trata de diseccionar los puntos más importantes de la relación educativa desde la configuración de una serie de disyuntivas y tensiones cuyo análisis resulta crucial para su desarrollo y puesta en práctica. Las mismas se definen desde estos siete pares conceptuales desde los cuales toman forma diversos aspectos muy significativos para la relación educativa: objeto-sujeto, intencionalidadfuncionalidad, influencia-autonomía, responsabilidad-libertad, autoridad-disciplina, confianza-respeto y singularidad-colectividad. Finalmente, profundiza en claves vinculadas a la relación educativa en el marco de la pedagogía de la alteridad, estableciendo una serie de dimensiones que se ponen en diálogo con las tensiones presentadas, apostando por desgranar la relación educativa desde una pedagogía de la relación sensible, una pedagogía de la escucha y una pedagogía de la invitación desde cuyas disyuntivas emerjan categorías que nos ayuden a entender más sustantivamente esas 
dimensiones relacionales desde la alteridad: representación, corporeidad, solicitud e interrogación, para la dimensión relacional sensible; comprensión, contexto, experiencia y proceso, para la dimensión de escucha; y encuentro, diálogo, acción y promoción, para la dimensión de invitación. Por último, tras desgranar estas ideas se avanzan unas reflexiones finales a modo de conclusión.

Palabras clave: teoría de la educación; relación educativa; pedagogía de la alteridad; convivencia; filosofía de la educación.

\section{ABSTRACT}

This article proposes a journey through how educational relations are constructed from the perspective of the pedagogy of alterity. For this he begins by reflecting on how the educational relationship should be a central theme in the theory of education and what can be some of its most important defining elements, starting from the analysis of the existing bibliography, fundamentally in the Spanish context. From there, it tries to dissect the most important points of the educational relationship from the configuration of a series of dilemmas and tensions whose analysis is crucial for its development and implementation. They are defined from these seven conceptual pairs from which various very significant aspects take shape for the educational relationship: object-subject, intentionality-functionality, influence-autonomy, responsibility-freedom, authority-discipline, trust-respect and singularity-collectivity. Finally, it delves into keys related to the educational relationship in the context of the pedagogy of alterity, establishing a series of dimensions that are put in dialogue with the tensions presented, betting on breaking down the educational relationship from a pedagogy of the sensitive relationship, a pedagogy of listening and a pedagogy of invitation from whose dilemmas emerge categories that help us to understand more substantively those relational dimensions from alterity: representation, corporeity, request and interrogation, for the sensitive relational dimension; understanding, context, experience and process, for the listening dimension; and meeting, dialogue, action and promotion, for the dimension of invitation. Finally, after shelling these ideas, some final thoughts are advanced by way of conclusion.

Keywords: theory of education; educational relationship; pedagogy of alterity; coexistence; philosophy of education.

\section{INTRODUCCIÓN}

Meirieu (1998, p. 20) nos interpelaba en un magnífico libro con esta sugerente a la vez que inquietante pregunta: "¿Se puede ser educador sin ser un Frankestein?". El presente texto pretende recoger el testigo, al menos en parte, de este interrogante, partiendo de la consideración de que la relación educativa es sin duda uno de los «nudos gordianos» de la Teoría de la Educación y un eje prioritario en la construcción del conocimiento pedagógico, el cual es necesario reivindicar a la luz de las 
múltiples, y a menudo poco consistentes, críticas que está sufriendo de manos de un antipedagogismo bastante extendido, como con acierto ha analizado Gil (2018). En este sentido, estas palabras pretenden reivindicar uno de los papeles principales de la teoría, específicamente el que la entiende como sustrato que fundamenta, da sentido y guía la acción educativa, en este caso circunscribiéndonos al ámbito relacional; pero eso sí, dejando claro que no se hace este análisis minusvalorando la adquisición del conocimiento ni obviando lo ético, pues igual que la negación de la trascendencia educativa de la forma de relacionarnos y convivir se puede considerar un dislate, sería un gran error que "para educar, dejemos de dar importancia a saberse las tablas de multiplicar y a robar» (p. 41). La Teoría de la Educación no debe ser ajena a ambas, aunque aquí nos centremos en la relación educativa.

Responder a cuestiones tales como qué hace que una relación podamos considerarla y adjetivarla como educativa o qué la distingue de otras relaciones sociales, sin duda ha supuesto un esfuerzo importante abordado por estudiosos de gran prestigio. Recogiendo parcialmente el testigo, y a partir de algunas de las preguntas iniciales que nos podemos plantear para comenzar a abordar este fascinante tema, vamos a intentar repensar la relación educativa ofreciendo algunas claves para visualizar mejor a qué nos referimos con este término y qué implicaciones puede tener ese discernimiento, tomando como referencia fundamental el amplio recorrido que desde la Teoría de la Educación en el contexto español ha tenido. Desde esta base, las reflexiones que obtengamos pueden suponernos cambiar parte de nuestras miradas hacia lo educativo, miradas que se deslicen (aunque esto no significa que la mirada no pueda terminar de abarcarlo todo) desde el "hacer cosas» hacia el «relacionarnos con». Como planteaba Sidorkin:

Una vez que percibamos las relaciones como un texto y las acciones como un contexto, podremos obtener una imagen muy distinta de la educación. Lo que importa no es lo que hacemos con los estudiantes sino qué tipo de relaciones construimos con ellos y entre ellos (2007, p. 108).

Resulta fundamental darle cada vez más importancia a este tema y a los desafíos que le plantea a los y las docentes, más si cabe en el marco de nuestras complejas sociedades. Sin duda no es un tema inédito, tratado fundamentalmente desde la Teoría de la Educación en España, pero no por ello debe dejar de tratarse y repensarse, dado lo crucial del mismo y teniendo presente diferentes argumentos, entre los que se van a destacar tres:

Un primer argumento se deriva de la consideración de señalar este campo como uno de los espacios que deberían ser más fecundos para la Teoría de la Educación en el futuro. Y no sólo por las «modas» sobre la educación emocional, todo lo convivencial e incluso lo vinculado con la educación y los derechos humanos, sino porque somos en sociedad, somos seres culturales que nos hacemos en las relaciones y la convivencia es uno de los grandes retos que se asoman en el horizonte. Hay que pensar en las relaciones y corporeizar a los sujetos de la educación, sin por ello 
dejar de nombrar que es desde ahí también donde se genera, trasvasa y construye el conocimiento, de manera que desde la Teoría de la Educación se nos iluminen sendas de desarrollo, aparte de las más obvias y/o ya iniciadas, para comprender y explicar la realidad educativa, realidad que es sin duda relacional.

También es necesario introducir en el argumentario la dimensión universitaria, pues se trata de un tema recurrente en la formación inicial de las y los profesionales de la educación. Como ya indicaran Prats y Vilafranca (2010), los planes docentes de la asignatura de Teoría de la Educación (y otras de títulos análogos o similares) acostumbran a centrarse en cuatro ejes temáticos, uno de los cuales tiene que ver con la descripción de los elementos que configuran el fenómeno educativo, dentro de los cuales se destaca la relación educativa. Los temas que tratamos académicamente deben estar siempre vivos, siempre en revisión, porque la realidad muta y los protagonistas del hecho educativo lo son en la medida que se relacionan.

Una tercera cuestión a tener en cuenta está presente en el ámbito sociológico y los cambios en las formas de relación derivadas sobre todo de los usos de internet y las redes sociales. Cambios en las concepciones de intimidad y extimidad, cambios en la forma de acercarnos y acceder a la información (cada vez más fragmentada y difusa, requiriendo una creciente capacidad crítica y de discernimiento que debe ser abordada pedagógicamente) y construir conocimiento, cambios desde las peculiaridades de los procesos educativos virtuales, cambios en los hábitos de acercarnos al otro/a, de conocerlo, de aprender, etc. Repensar la relación educativa debe conllevar también contemplar estas cuestiones desde una pedagogía de la alteridad, para lo cual las herramientas intelectuales de la Teoría de la Educación son más necesarias que nunca.

En definitiva, se trata de una temática de amplia incidencia en múltiples campos más allá del pedagógico, pasando por el literario, el psicológico, o el cinematográfico. Por ello establecer relaciones educativas, acto estrechamente vinculada a crear climas educativos en el aula, es fundamental para el buen desarrollo de la acción educativa, casi un prerrequisito si hablamos de la educación escolar.

\section{SituÁndonOS: LA RELACión EDUCATIVA Y LA TEORÍA DE LA EDUCACión}

José Manuel Esteve, en un hermoso y breve texto titulado "La urdimbre de la relación educativa", que presentó en su último Seminario Interuniversitario de Teoría de la Educación, daba con algunas de las claves centrales de la cuestión, a saber:

se trata de una relación que tiene en sí una finalidad que de alguna manera tiene como objeto al educando; pero que tiene que contar a cada paso con la condición de sujeto que le corresponde como persona. Corremos en cada instante el riesgo de olvidar al sujeto y hacerlo un mero objeto de condicionamiento; y al mismo tiempo, en la vertiente opuesta, el riesgo de olvidar la construcción de la personalidad, haciendo banal la relación, y olvidando dirigirla hacia una finalidad intencional elegida (Esteve, 2009, pp. 2-3). 
Esto implica que nos movemos siempre, como educadoras y educadores, en un difícil equilibrio entre el dogma y la libertad de pensamiento, entre la autonomía y la sumisión, entre la creatividad y el mecanicismo en el quehacer educativo.

Al hilo de lo anterior, uno de los aspectos centrales de estas que empezaremos a llamar "disyuntivas o tensiones pedagógicas» tiene que ver con el desarrollo de la autonomía del educando, y específicamente con el desarrollo de la autonomía moral, entendida como capacidad de tomar decisiones, de discernir desde nuestra propia responsabilidad personal para que nuestras reflexiones y acciones se den en un marco intencional y con fines, al mismo tiempo que teniendo en cuenta las consecuencias de las mismas, dotándolas así de sentido. Para el desarrollo de la misma, coincidimos de nuevo con Esteve al señalar que:

Una de las peores patologías de la relación educativa consiste en querer prolongar la situación de dependencia. Educamos para la autonomía. [...] Reconocer su autonomía y aceptar que tomen sus propias decisiones es la prueba definitiva de que hemos tenido éxito en la relación educativa (2010, p. 130).

Por tanto, la relación educativa desde la óptica de la de los derechos y la autonomía del educando se encuentra basada en unos principios donde la confianza en las competencias del otro u otra, las expectativas positivas en sus logros, resulta fundamental, pues las mismas condicionan las respuestas que obtenemos de los y las demás. Y es que los espacios relacionales de calidad se construyen a partir de la calidad de las relaciones que los configuran. Por eso la relación intelectual y emocional en el aula debe entenderse como fundamental para contribuir a mejorar la calidad de la educación. (Maturana y Nisis, 1997)

De ahí que la generación de espacios democráticos que primen la construcción identitaria en libertad y la educación para la autonomía moral sea una cuestión de ineludible asunción en la reflexión teórica de la educación, ya que

el práctico tiene que tomar decisiones y elaborar juicios reflexionantes, precisamente porque hay incertidumbre, porque nada está dado de antemano, porque tiene que atravesar, por sí mismo, la praxis que realiza, y porque tiene que aprender en qué consisten sus artes (Bárcena, 2005, p. 184).

Claro está que todo lo anterior debe ser contextualizado para que cobre un sentido de autenticidad, por lo que no podemos hacer los análisis de forma ajena al contexto socioeconómico en el que estamos insertos, así como a la pluralidad cultural que conforma los espacios sociales, incluida la escuela, y la necesidad de recordarnos permanentemente que el alumnado no es una entelequia o idealización, sino seres humanos de carne, huesos, pensamientos y emociones. Como decía Postic:

El acto de enseñanza no está centrado en el alumno «medio» siguiendo un cauce predeterminado del que no puede salirse. Es personalizado. [...] Saber cuáles son los rasgos cognitivos y afectivos del alumno, para proporcionarle una ayuda personalizada, tal es la preocupación de aquellos que buscan llegar más allá de la didáctica diferenciada. 
No se trata de un simple apoyo técnico, que se reduciría a ver cómo se puede adaptar un mensaje cognitivo a las características del receptor, se trata más bien de acoger a la persona en su originalidad para caminar con ella (2000, p. 117)

En todo caso, volviendo a la importancia de las preguntas, tenemos una importante que contestar: «Qué pasa si consideramos la educación como un proceso de construcción de relaciones?» (Sidorkin, 2007, p. 111) Pues supone, entre otras cosas, considerar los procesos como algo fundamental en educación, otorgarle el lugar que se merece a la presencia del otro-a en la acción educativa, entender el aprendizaje como algo no sólo vinculado con el «hacer» y "pensar», sino también con el sentir, el convivir y el cuidar.

Todas estas cuestiones deben estar presentes en nuestra reflexiones en relación a este tema, pero igual va siendo hora de acudir a algunas definiciones de interés sobre la relación educativa, como las de Van Manen (1998), Postic (2000) y Jover (1991), de las cuales merece la pena extraer varios aspectos:

- La relación educativa es una relación intencional orientada hacia el desarrollo personal del niño-a, implicando la necesidad de considerar sus experiencias, situación y darle valor, incluyendo la introducción de dosis de responsabilidad cada vez mayores en ellos.

- Esta relación posee características cognitivas y afectivas identificables, teniendo además un desarrollo y una historia, con las implicaciones que esto tiene.

- Además, podemos considerarla una relación de ayuda, lo que implica una asimetría en las relaciones y una orientación hacia una finalidad que trasciende la misma relación.

Por tanto, parece claro por un lado que la relación educativa es mucho más que una interacción didáctica, está relacionada con el establecimento de climas positivos en las aulas y no tanto en lo que hace el maestro o maestra o lo que le pasa al alumno o alumna, "sino en lo que media entre uno y otro, en la relación de comunicación -entendida esta en sentido amplio- que está presente en todo fenómeno educacional» (Martínez, Esteban, Jover y Payá, 2017, p. 166). Todos y todas podemos acordarnos de frases o gestos, incluso aparentemente imperceptibles, que han condicionado las vidas de docentes y alumnos y alumnas, su propio futuro, porque lo que hacen y dicen los maestros y maestras determina la manera de relacionarse con el otro-a que es discípulo, y a su vez, hay que tener en cuenta que un clima deficiente, tenso, atemorizado, desautorizado moralmente o de poca confianza, convierte las mejores acciones o discursos en carentes de sentido, perjudiciales o provocadores del efecto contrario al deseado. Por ello, se puede afirmar que, en gran medida, y aunque la realidad no se ajuste a esto, "los educadores deberían concentrarse en establecer relaciones eficaces y sólo después preocuparse por lo que hacen» (Sidorkin, 2007, p. 15).

Esto nos lleva a las características de la relación educativa. Para Jover (2013), estas serían tres: ayuda, asimetría e intencionalidad, como emanaba de su definición. 
Las mismas podemos completarlas con los aspectos de la relación educativa destacados por Romero, Bernal y Jiménez (2009), que son: confianza, seguridad, comunicación, textura afectiva, autenticidad, clima positivo, responsabilidad, voluntad de permanencia, aprendizaje cooperativo, influencia, empatía y mutuo reconocimiento. Y a su vez, podemos ampliar esta panorámica a través de Bárcena (2005, p. 136) cuando afirma que «relacionarnos, en educación, con los que se educan implica tener presente al menos tres cualidades: la presencia del otro, su diferencia, la equilavencia de su discurso".

Ese reconocimiento del otro-a desde su diferencia, respetando y valorando la misma, atendiendo a que la asimetría de la relación no pueda nunca transformarse en desigualdad, es fundamental para entender las relaciones educativas, teniendo presente también aspectos como los siguientes:

- No existen recetas en las relaciones educativas, que son singulares y cambiantes (para una misma relación, los momentos o contextos de la misma pueden ser determinantes para que no sirva lo ya utilizado anteriormente), si bien puede haber principios que nos dirijan con más claridad a trazar sus mapas.

- Saber escuchar y responder sin prejuicios, siendo capaz de oir incluso lo no dicho por la otra parte por falta de posibilidad, capacidad o deseo, es una cualidad fundamental que ayuda a construir relaciones educativas.

- El diálogo es el tipo de relación más beneficiosa en los encuentros educativos, por lo que hay que prestar especial atención a la reconciliación de la relación dialógica con la asimetría de poder de partida (Sidorkin, 2007).

- Las interacciones en la relación educativa crecen o menguan, fluyen o se interrumpen, se modifican o se enquistan según el modo de emisión y de recepción de los comportamientos, discursos o acciones, por lo que para su análisis es importante atender a las señales de la vida real del aula al respecto (Postic, 2000).

- Por desgracia, la relación educativa se ve lastrada por la "presión» del academicismo y sus urgencias, en forma de objetivos y rendición de cuentas para medir el rendimiento académico como referente máximo de lo educativo en el ámbito escolar.

- Los maestros y maestras deben retomar el protagonismo de la relación, puesto que ésta no puede dejarse en exclusiva a la construcción del alumnado, rehuyendo o inhibiéndonos por considerar muy compleja la tarea. Como dicen Romero, Bernal y Jiménez: 
Permítasenos la metáfora: es como si los médicos rechazasen a ciertos enfermos porque sus enfermedades les parecen demasiado graves. [...] Los medios materiales, las metodologías, los contenidos de la enseñanza, todo pierde su sentido si no se establece una auténtica relación educativa (2009, p. 135).

- Fundamental entonces es lo que Van Manen llama el "tacto pedagógico", que se vincula con la capacidad de adaptarnos a los contextos, a las historias de cada alumno o alumna, a sus motivaciones, a sus necesidades de aprendizaje, a su manera de ver el mundo, a sus peculiaridades en la construcción del conocimiento, a sus convicciones morales, etc. Como dice Asensio (2010):

El profesor que actúa con tacto sabe suavizar las asperezas que surgen de la convivencia en las aulas, interpretar lo que conviene hacer para superar los momentos de fatiga, ganarse la autoridad y el aprecio que precisa para poder influir en sus alumnos y reorientar los comportamientos inadecuados. Pero todo ello no se logra tan sólo echando mano de los manuales, sino siendo aquello que propone, aprendiendo a interpretar las demandas afectivas de unos escolares concretos, sus posibilidades cognitivas del momento, sus formas de reaccionar, sus aspiraciones, sus temores y sus esperanzas. Es decir, valorando el conjunto de comportamientos, motivos, sentimientos y expectativas que emergen en las interacciones educativas (p. 117).

- La relación educativa, como veremos más específicamente, busca la autonomía del alumnado, su progreso actuando si acaso como los «andamiajes» que definiera Bruner, se aparta de la reproducción acrítica y la imitación indolente del modelo educativo. Por eso hay que huir del educador o educadora que

no actúa más que en el sentido de sus propios intereses, de sus preferencias, si manipula la incitación, la persuasión [...], entonces utiliza el poder que le ha sido dado institucionalmente y busca la dependencia del alumno para reforzar la imagen de su poder y para persuadirse a sí mismo de él (Postic, 2000, pp. 109-110).

\section{DisYUNTIVAS Y TENSIONES EN LA RELACIÓN EDUCATIVA}

De todas maneras, las claves ofrecidas desde el pensamiento inicial de Esteve y las otras referencias enunciadas aquí nos van a sevir también para profundizar en la relación educativa a partir de una serie de disyuntivas o tensiones (en el sentido planteado por Meirieu (2004, p. 87), es decir, «utilizado como metáfora para describir el estado de un educador que debe hacer frente a exigencias contradictorias y no puede, sin ser incoherente, abandonar ninguna», ya que "la pedagogía trabaja especialmetne sobre las contradicciones consubstanciales al acto educativo", desde las 
cuales podemos otear sus horizontes con más claridad para así conseguir construir un "a modo de mapa» de la misma. Desde aquí, vamos a considerar que las disyuntivas y tensiones principales vinculadas con las relaciones educativas son las siguientes:

\subsection{Objeto-sujeto}

La relación educativa tiene como objeto de conocimiento un sujeto, o mejor dicho, su finalidad en cierto sentido tiene como objeto al educando, en el sentido de que hay una intencionalidad en la relación teleológicamente marcada y definida, pero precisamente ese fin asumido no puede obrar al margen de la persona a la que se dirige. Esto, podría decirse, constituye una cierta paradoja, pero más bien lo que nos indica es la necesidad de establecer, como en todo lo que esté relacionado con lo educativo, equilibrios con vocación de estabilidad, donde el sujeto sea percibido, tratado y valorado como persona, desde sus singularidades y potencialidades, sin por ello perder de vista que lo que se pretende es su desarrollo integral, para lo cual el objetivo no debe lastrar la relación ni tampoco la relación puede diluirlo. En palabras de Esteve:

Existen, por tanto, dos exigencias difíciles de conciliar en la relación educativa. Se trata de una relación que ha de tener una finalidad que, de alguna manera, convierte al niño en objeto de nuestra acción; pero, al mismo tiempo, tiene que contar con el respeto a su libertad y a su dignidad, a la condición de sujeto que le corresponde como persona (2010, p. 111).

Una de las claves para intentar ese equilibrio es ser consciente de que lo específico de la relación educativa no es en sí el tener un objetivo, sino qué clase de objetivo, porque en ella la intencionalidad posee un carácter educativo que pretende que el educando se desarrolle leyendo el mundo, haciendo suyo lo que le rodea desde su identidad y reconstruyéndola también desde ese proceso de lectura. Por tanto, podemos decir que acoge al educando y le muestra el mundo, procurando dotarle de herramientas para comprenderlo y transformarlo al mismo tiempo que se comprende y se transforma a sí mismo y a las demás personas y contextos con los que interactúa, siempre desde la máxima de que «respetar al educando no es sólo acogerlo tal como es, sino también, y sobre todo, ayudarle a superarse esforzándose a ser el que puede ser» (Jover, 1991, p. 158).

\subsection{Intencionalidad-funcionalidad}

Muy vinculado con lo anterior, y de alguna manera ya comentada, está la diatriba de la relación educativa a través de la cual la misma se contornea dibujando aristas entre su carácter funcional, derivado de ser una relación intencional, y la deriva que supone llevarla al terreno meramente utilitarista por un lado o especulativo por otro. El equilibrio aquí se encuentra en un nudo corredizo en la cuerda que 
marca la meta funcional planteada y el carácter libre de coacciones que debe tener una relación educativa.

\begin{abstract}
La educación no consiste en una pura relación personal, como es la amistad, porque entre el educador y el educando se interpone la intencionalidad, pero tampoco en una pura relación funcional, en la que los sujetos particulares, con sus temores y deseos, puedan ser anulados en aras de la objetividad [...] Ello es así porque la intencionalidad de la educación tiene un carácter distintivo que podemos designar como la orientación al mundo para el educando (Martínez et al., 2017, p. 41).
\end{abstract}

\title{
3.3. Influencia-autonomía
}

Igualmente, hablar de intención conlleva hacerlo de influencia, algo intrínseco al acto educativo, "ya que incluso cuando el educador decide no intervenir directamente y poner las condiciones para que el niño avance realizando sus propios aprendizajes por descubrimiento, es esta actitud del educador la que permite la consecución de ese tipo de aprendizaje» (Esteve, 2010, p. 102). Se trata de algo evidente, porque, dicho con mayor contundencia, «en el fondo, la relación educativa es manipuladora, aunque con la mejor de las intenciones». (Sidorkin, 2007, p. 175)

¿De qué influencia o influencias hablamos? Si nos centramos en el ámbito escolar, podemos afirmar que el alumno o alumna, en la relación educativa, es atraído por la influencia del maestro o maestra y la de sus iguales, adoptando en mayor o menor medida los modelos ofrecidos por unos u otros (Postic, 2000). Entonces, ¿dónde está la clave para que esa influencia sea positiva? En la medida en que posibilite y fomente la autonomía del sujeto, ya que en la relación educativa

la dependencia tiende a aniquilarse a sí misma, a lograr una situación en la que la dependencia desaparezca; sin tal inclinación ésta deja de ser educativa. [...] La dependencia en la relación educativa se orienta hacia la libertad del educando, quiere hacerlo libre (Jover, 1991, p. 153).

Más poéticamente lo dijo Hölderlin, con el que diríamos, parafraseándolo, que el educador o educadora debe hacer como las olas del mar, llegar (llevar) hasta la orilla y retirarse.

Educar para la autonomía, hay que insistir en ello, será algo inherente a la relación educativa, por lo que ésta debe huir de prescripciones acríticas, del «ordenoy-mando", de dictar lo que es adecuado o no, así como de llevar al educando a un terreno donde haga las cosas simplemente por agradar o satisfacer al educador-a o porque «es lo que hay que hacer». Ser autónomo o autónoma tiene que ver con eso, partiendo de la inconmensurabilidad del ser y la dignidad humanas, que nunca pueden ponerse en entredicho en la relación educativa. Además, desde el punto de vista moral, ser autónomo o autónoma está vinculado con nuestra capacidad de decidir lo que hacemos y por qué lo hacemos, siendo consecuentes y responsables 
de nuestras decisiones y de las consecuencias que tienen. Por eso, coincido con Freire (2006) en la importancia que tiene:

Saber que debo respeto a la autonomía, a la dignidad y a la identidad del educando y, en la práctica, buscar la coherencia con este saber, me lleva inapelablemente a la creación de algunas virtudes o cualidades sin las cuales ese saber se vuelve falso, palabrería vacía e inoperante (p. 61).

Y volvemos a la cuestión de los equilibrios. En este orden de cosas, esta disyuntiva es abordada con acierto en un libro colectivo sobre la pedagogía Freinet:

¿No es absurdo rechazar o negar un poder que el adulto tiene efectivamente si ese poder permite armar al niño, a su vez, del poder que viene de saber leer, de saber razonar, de saber hablar, de saber vivir con los demás? La mayor exigencia que debemos únicamente mantener, ¿no es la de aceptar lúcidamente este poder, trazar los límites y no abusar? (VV.AA., 1981, p. 15).

La influencia puede ser poder sobre el otro o la otra (la mayoría de las veces es así, sobre todo por la situación asimétrica que en sí supone de partida la relación educativa, como hemos comentado), por lo que en nuestras manos está fijar los límites de esa influencia, y hacerlo precisamente con el referente de la autonomía resulta un criterio sensato y sensible hacia el otro-a, fomentando con ello aspectos como la inteligencia crítica, el hacer responsable, la adquisición de unos conocimientos que aporten comprensión a cuanto nos concierne y una prudente confianza en nuestros propios juicios (Asensio, 2010).

Por todo esto, puesto que la acción define en cierta forma la identidad del sujeto y está íntimamente vinculada a la autonomía, que a su vez se desarrolla desde el reconocimiento del individuo como sujeto de derechos. Por esto, derechos y autonomía son dos términos con una buena dosis de reciprocidad en la práctica, que debe ser tenida en cuenta también en la configuración de la relación educativa desde el reconocimiento de la diversidad y la pluralidad, entendido todo esto como valores, en la acepción de algo valioso de ser promovido desde la educación.

\subsection{Responsabilidad-libertad}

Aludíamos antes a la responsabilidad disertando sobre la educación para la autonomía desde la relación educativa, lo que nos lleva a la diatriba del vínculo entre responsabilidad y libertad en la relación educativa. Sin duda se trata de un asunto filosófico y ontológico de primer orden, del que ya Nassif (1980) nos advertía de alguna manera:

La educación para la libertad, la responsabilidad y la autodisciplina es, quizás, la mayor encrucijada de la escuela contemporánea, sobre todo si no existe en maestros y pedagogos una correcta comprensión de las metas finales y del necesario desbloqueo de las instituciones docentes. Si esa concepción falta pueden producirse graves deformaciones, 
como la fractura entre autonomía personal y servicio social (no sólo a la sociedad presente, sino además y, muy en especial, a la futura). Es inconcebible el cumplimiento del destino personal fuera de la sociedad. Tanto como creer que la sociedad sea realizable sin personalidades enriquecidas que la fecunden (p. 208).

Siempre se ha hablado de la gran responsabilidad que supone educar, cosa que resulta incuestionable por todo lo que se pone en juego en esa acción, pero no es menos cierto lo que decía Esteve (2010, p. 183): «educar para la libertad es siempre educar en libertad». Educar responsablemente es hacerlo mirando a los intereses y necesidades del educando, generar relaciones de confianza mutua y de cuidado, al mismo tiempo que sólo puede ejercerse así desde la libertad propia y para la libertad del otro u otra, puesto que "La ética no comienza con una pregunta, sino como una respuesta a la demanda del otro hombre. La responsabilidad, entonces, es la condición de la libertad, es una responsabilidad anterior a todo compromiso libre» (Bárcena y Mélich, 2000, p. 139).

\subsection{Autoridad-disciplina}

La antítesis de la libertad la supone el ejercicio del autoritarismo, que muchas veces se confunde con la autoridad, y que en todo caso parece llevar adosada la cuestión de la disciplina, todos ellos aspectos de sumo interés para seguir enmarcando la relación educativa. Hay entonces que partir de una diferenciación clara de ambos términos para comprender esta diatriba en el proceloso mar que estamos surcando de la relación educativa:

- El autoritarismo se impone, mientras que la autoridad se consigue a través de la relación.

- El autoritarismo fomenta la dependencia y la autoridad, la autonomía.

- El autoritarismo destruye la libertad y la autoridad, la acoge.

- El autoritarismo busca la obediencia y la sumisión y la autoridad, la disciplina, permitiendo la reflexión sobre las normas y el desarrollo del sentido crítico (Esteve, 2010).

- El autoritarismo se basa en relaciones antipedagógicas y la autoridad, en el tacto pedagógico.

- El autoritarismo puede conducir al éxito académico, pero nunca al social ni personal. Noddings (2001) afirma que el éxito académico sin el afecto positivo es moral y estéticamente vacío, mientras que la autoridad permite desarrollar un

concepto de orden que corresponde a la auténtica relación educativa (que) es el que se deriva de una disciplina justa, en la que la reflexión sobre las normas 
conduce a nuestros hijos y a nuestros alumnos a interiorizar los valores que justifican las normas (Esteve, 2010, p. 155).

Por lo tanto, atendiendo a estas ideas, podemos decir desde el ámbito académico la afectividad, el mundo de las emociones entrelazadas que se configuren en el aula, define la posibilidades de influencia y de reconocimiento de autoridad por parte del alumnado y viceversa, dentro de la asimetría relacional inherente a la función docente.

En este sentido, autoridad y disciplina pueden ser complementarias en la relación educativa, porque ante una figura de autoridad, nunca impuesta sino aceptada y reconocida como tal, la disciplina está más vinculada con el diálogo, la confianza y el respeto mutuo que con formas anquilosadas de ejercicios de poder. La autoridad legitima porque para seguir siendo autoridad partirá siempre en la relación educativa de los derechos del otro-a. Por eso decimos que la autoridad hay que ganársela todos los días y, relacionándolo con la intencionalidad de la autonomía de ese otro-a, debe tener vocación futura de trasvase, es decir, debe tener como horizonte que el educando sea fuente de autoridad a su vez.

\subsection{Confianza-respeto}

Ya lo hemos advertido, pero no por ello deja de ser necesario remarcarlo específicamente: sin confianza y sin respeto no es posible la relación educativa. Son en cierto sentido dos caras de una misma moneda. La confianza hay que entenderla como fundamento de la convivencia, y desde un punto de vista pedagógico supone un elemento crucial, porque tiene la capacidad de hacernos mejores, porque mejora la autoconfianza, porque supone la antesala de la acción y la multiplicación de nuestras posibilidades futuras. Por contra,

La falta de confianza del educador puede obstaculizar la consecución de objetivos educativos. Puede, así, impedir el desarrollo de la autonomía del educando, dificultando el devenir natural de la relación educativa. [...] Pero el educador no sólo influye en la imagen que el alumno se forma de sí con su confianza, sino también con su ejemplo (Jover, 1991, p. 159).

Y en cuanto al respeto, partiendo de la concepción kantiana de nuestro deber para tratar a los y las demás como un fin y no sólo como un medio, hace hincapié en la negación de toda relación que implique dependencia o inacción amparándose falsamente en no inmiscuirse en la "libertad del otro-a". Esto último es importante, porque como hemos comentado, la relación educativa no elude su responsabilidad desde la influencia que supone para con el otro-a, sino que actúa desde la misma pero con el referente de sus derechos y el respeto escrupuloso a su ser-en-el-mundo. Mas esto no puede llevarnos nunca a decantar la balanza hacia un paidocentrismo extremo o complaciente, que sobre todo en el ámbito familiar y en ciertos sectores 
del escolar, está emergiendo cada vez con más fuerza y que rompe absolutamente con la noción de relación educativa aquí promovida. Desde esta óptica:

Un desmedido protagonismo del alumno o una errónea interpretación de lo que significa conducen a un paidocentrismo que sitúa en el centro de la práctica educativa los intereses más motivadores para el alumno, cuando lo que debe situar es su actividades de aprendizaje [...] Y en esta tarea, ir a contracorriente consiste en regular adecuadamente el protagonismo del alumno y no dejarse llevar por tendencias que eviten cualquier contrariedad y esfuerzo en la tarea de aprender. Para lograr este objetivo es importante, en primer lugar, que el docente confíe en las posibilidades de sus alumnos y tenga expectativas altas sobre sus capacidades de aprendizaje; y en segundo lugar, que confíe en sus propias capacidades como docente y educador para estimular el esfuerzo y la superación necesarios en sus alumnos y así poder conducir la práctica educativa en función no del interés inmediato, sino del aprendizaje profundo de sus alumnos (Martínez et al., 2017, p. 187).

\subsection{Singularidad-colectividad}

La última diatriba planteada emerge de la experiencia, de la necesidad de mirar, de fijarnos, de partir de las experiencia propias y ajenas, en definitiva, de nuestras historias de vida, para que la relación educativa cobre sentido y provecho. De hecho, la relación educativa es en sí una experiencia, una experiencia educativa donde una parte fundamental de lo que se aprende es la relación en sí misma:

Si lo que un maestro enseña es, ante todo, una relación, es decir, su propia capacidad de apertura y de escucha, entonces sólo podemos aprender desde el compromiso con esa relación. Lo importante para el "aprender» es el tipo de relación "educativa» que establecemos (Bárcena y Mélich, 2000, p. 179).

Y para ello los equilibrios a conseguir tienen que ver con la atención a las singularidades sin perder de vista el sentido social de toda acción educativa. Por ello es importante, por un lado, tener en cuenta que si «en la relación educativa» se pierde «la atención a lo singular» como horizonte de sentido, ocurre que la mirada hacia el otro queda anclada en "lo que necesita" (Molina, Blanco y Arbiol, 2016, p. 140), que suele focalizarse en "carencias» y termina por descontextualizar las relaciones, privándolas de las experiencias e historias que configuran lo que son los alumnos y alumnas y docentes y explican cómo han llegado a serlo. Y esto está también intrínsecamente relacionado con la cultura escolar, su construcción y posibilidades de cambio, donde el profesorado tiene un papel protagonista, pero sin dejar de lado las cuestiones institucionales, macropolíticas y micropolíticas, las sociales y las específicamente relacionales (Barba, 2002).

Por supuesto, se están planteando estas cuestiones no como excluyentes, sino como dos polos de atención ineludibles a la hora de enfrentarnos a la relación 
educativa, relación que en definitiva supone ver lo potencial desde lo singular mirando desde lo colectivo y contextual.

\section{LA RELACión EDUCATIVA DESDE UNA PEDAgogía de LA ALTERIDAd}

Dos personas están paseando por la orilla del mar cuando observan un extraño fenómeno. Montones de estrellas de mar han sido arrastradas por las olas hasta la playa. Muchas están ya muertas, ahogadas en la arena sucia bajo un sol de justicia. Otras siguen intentando separarse con sus brazos de la abrasadora arena para pospone un tanto su muerte segura. «iEs horrible -dice uno, pero así es la naturaleza!». Entretanto, su compañero se ha inclinado y examina con detenimiento una estrella concreta, al tiempo que la levanta de la arena. "QQué haces - pregunta el primero-, no ves que con esto no puedes solucionar nada? De nada sirve que ayudes a una». «Le sirve a esta!», se limita a decir su compañero, mientras devuelve la estrella al mar (Van Manen, 2004, p. 16).

Esta maravillosa historia de Van Manen supone una invitación y una justificación a este epígrafe. Si la educación sólo cobra sentido y ser en la relación con el otro-a, en el hacernos cargo de él, en acompañarle, en ayudarle, será importante vislumbrar a qué nos podemos referir con una pedagogía de la alteridad (Bárcena y Mélich, 2000; Ortega, 2004; Vila, 2006), de inspiración levinasiana, que nos permita hacer visible esa relación y sus consecuencias y connotaciones educativas, asumiendo en el seno de la misma la presencia de una ética de la compasión y de la empatía (Prieto, 2011; Ortega, 2016).

No podemos olvidar que la relación de alteridad podemos circunscribirla desde lo ontológico, lo social y lo ético (Vila, 2006). En el primer caso, la mirada ética se da desde la presencia o la ausencia de un ser semejante; desde el reconocimiento, la afirmación recíproca, la valoración de su diferencia y el sentido de su identidad, tal y como es, sin condiciones ni excusas, sino como cómplice en ese proyecto común e intercultural que denominamos humanidad. Desde lo social hablaremos de una dimensión política e incluso normativa, en la medida en que el otro nos exige la dimensión colectiva de la ética al implicar también la presencia de un tercero: «El tercero me mira en los ojos del otro» (Lévinas, 1987, p. 226). Y en el caso de la ética, evidentemente hay que hacer referencia a una relación de responsabilidad y complicidad, pero también a algo más, puesto que la alteridad no es sólo una característica de lo ético, sino que construye su sentido y constituye su esencia. La pregunta, por tanto, se traslada a un plano relacional donde:

El secreto de los otros, si es que existe, residiría más bien en la idea que ellos mismos se hacen del otro (o que no se hacen, o que se hacen con dificultad), porque aún constituye el medio más simple de pensar en lo mismo y lo idéntico. Pero, entonces, ¿el secreto de los otros no es también el nuestro? (Augé, 1996, p. 30) 
Por supuesto, la respuesta sería afirmativa, porque la comprensión de la alteridad emerge desde el encuentro entre lo propio y lo otro que se hace presente frente a nosotros.

Las palabras clave en ese encuentro son diferencia, comprensión, reconocimiento y equidad: la diferencia que nos constituye como humanos y legítimos desde nuestra identidad; la comprensión desde su papel mediador en la construcción e interpretación de la alteridad como hecho social intrínseco a la heterogeneidad; el reconocimiento como elemento necesario para no sólo legitimar la presencia del otro o la otra sino para valorarla desde el convencimiento de su inconmensurabilidad y necesidad para la convivencia; y la equidad para no olvidarnos de que la igualdad requiere de la misma y suma así para la convivencia y el establecimiento de relaciones más positivas e incluso educativas. En esta línea, también es de interés el trabajo de Pallarés y Chiva (2017), los cuales reflexionan sobre la importancia de una pedagogía de la presencia, rescatando así una manera de interpretar la educación como proceso de reajuste del sujeto de la experiencia, entendiendo que es el sujeto que aprende quien produce su propia presencia en la experiencia de su aprender.

En este contexto resulta imprescindible la permanente consideración y presencia del otro y la otra en educación, y desde esa perspectiva reconozco como asunto prioritario ir desarrollando una pedagogía de la alteridad que recoja esto. Así, hablar de la ética como un aspecto no sólo ineludible o incluso imprescindible, sino consustancial al hecho educativo, debe implicar el entrar a considerar un paso previo a lo deontológico (en el sentido kantiano), en la medida en que la ética que debe definir una pedagogía de la alteridad no puede ser en primer lugar sólo un deber "externo" (y mucho menos una imposición), sino algo intrínseco a la propia forma de ser en y de la acción educativa y sus protagonistas, una manera de dar respuesta al otro o la otra en un contexto concreto, desde una experiencia que haga visible al otro desde su propia alteridad y lo reconozca como legítimo otro en la convivencia (Maturana, 1994).

A su vez, esa pedagogía de la alteridad debe constituir una experiencia en la que se muestre la interiorización y apropiación que debemos hacer como educadores y educadoras del valor de la presencia del otro y de nuestra responsabilidad y compromiso para con el mismo, sin que medie en esa relación, como manifiesta Lévinas (1991), una espera de reciprocidad, ya que es una relación con sentido en sí misma desde su manifestación ética, como hemos ido comentando. En definitiva, dentro de este marco una pedagogía de la alteridad debe conllevar

ver el mundo desde la presencia del otro. Ello nos obliga a negar cualquier forma de poder, porque el otro (el educando) nunca puede ser objeto de dominio, de posesión o de conquista intelectual. En segundo lugar, exige la respuesta responsable, es decir, ética a la repuesta del otro (Ortega, 2004, p. 9). 
Partiendo de estas reflexiones hay que entender que esa pedagogía de la alteridad desde la relación educativa debe tener tres dimensiones principales que asuman la necesidad de sentir al otro, abrirse al mismo y verlo, visualizarlo y hacerlo partícipe así de un mundo compartido de significados y emociones. A su vez, esas tres dimensiones, relacionadas con una serie de valores a fomentar educativamente y que constituyen pilares para la relación educativa, estarían compuestas por cuatro categorías cada una, las tres primeras referidas a la esencia del acto pedagógico inherente a las mismas y la cuarta como principio de consideración y acción básico vinculado a cada dimensión. De manera más gráfica, podemos hacernos una idea de lo dicho a continuación, ampliando las ideas plasmadas en Vila (2006):

Tabla 1. La relación educativa desde la pedagogía de la alteridad

\begin{tabular}{|c|c|c|}
\hline DIMENSIONES & DISYUNTIVAS O TENSIONES & CATEGORÍAS \\
\hline $\begin{array}{c}\text { Pedagogía de la Relación } \\
\text { Sensible }\end{array}$ & $\begin{array}{c}\text { Representación } \\
\text { Corporeidad } \\
\text { Solicitud } \\
\text { Intencionalidad-Funcionalidad } \\
\text { Pedagogía de la Escucha }\end{array}$ & $\begin{array}{c}\text { Comprensión } \\
\text { Contexto }\end{array}$ \\
& $\begin{array}{c}\text { Influencia-Autonomía } \\
\text { Responsabilidad-Libertad } \\
\text { Autoridad-Disciplina }\end{array}$ \\
\hline $\begin{array}{c}\text { Pedagogía de la } \\
\text { Invitación }\end{array}$ & Confianza-Respeto \\
& Singularidad-Colectividad & $\begin{array}{c}\text { Encuentro } \\
\text { Diálogo } \\
\text { Acción } \\
\text { Promoción }\end{array}$ \\
\hline
\end{tabular}

Fuente: Elaboración propia

Por tanto, según la propuesta incluida en el cuadro anterior, una pedagogía de la alteridad, imbricada epistemológica y axiológicamente en la construcción de relaciones educativas, debe emerger de una pedagogía de la sensibilidad, una pedagogía de la escucha y una pedagogía de la invitación, las cuales se desarrollan brevemente a continuación, con la pretensión de aportar elementos de debate en torno a los principios que deben constituir la mirada desde la alteridad a las relaciones educativas. Al fin y al cabo, y parafraseando a Van Manen (1998), no podemos olvidar que la educación no es otra cosa que la fascinación por el crecimiento del otro.

Una Pedagogía de la Relación Sensible incluye nuestra forma de percibir y sentir, de aprender mediante la aprehensión (en el sentido vigotskiano) que nuestros sentidos hacen del mundo que nos rodea, y dentro de este orden de cosas se manifestarían las disyuntivas Objeto-Sujeto e Intencionalidad-Funcionalidad. Para ello debemos tener presente como categorías la Representación que hacemos de 
la realidad, conjugando lo sistémico y lo fenomenológico (sistemas y mundos de la vida, en la línea de Habermas (1987)), la Corporeidad como elemento que «materializa" las relaciones, la solicitud como exigencia ética de inspiración levinasiana, y la Interrogación como principio pedagógico básico para intentar comprender(nos), descubriendo de esa manera la esencia de la acogida (Ortega, 2004) y la interculturalidad (Vila, 2012) no sólo como actitud permanente sino como parte fundamental de toda relación educativa. De esta manera, una ética y una pedagogía de la alteridad para las relaciones educativas nos debe permitir hacer visible, acoger, reconocer y valorar al otro, un otro concreto en el espacio y en el tiempo (con un contexto y una historia), haciéndonos responsables de él o ella, de su presencia y desarrollo.

Una Pedagogía de la Escucha, puesto que educar desde la alteridad significa también abrirse al otro, dotarlo de voz y reconocerlo como elemento con valor en sí mismo, ya que "La pedagogía del silencio, la de escuchar, más que la de hablar, debería ser la primera lección práctica que todo profesor tendría que aprender» (Martínez et al., 2017, p. 45). En esta escucha activa, en esa comunicación permanente con el otro-a, deben fluir las disyuntivas Influencia-Autonomía, Responsabilidad-Libertad y Autoridad-Disciplina, como tres ejes fundamentales de cuyo equilibrio, en el sentido que se vislumbra en este texto, depende que podamos hablar realmente de relaciones educativas y donde probablemente se encuentren las claves de ser o no Frankenstein como docentes o, al menos, en qué medida. Para ello, categorías de análisis clave deben ser la Comprensión (cuestionadora, reorganizativa, solidaria) del otro-a, el Contexto que nos permite aterrizar las ideas y visibilizarlas en la acción de la relación educativa, la Experiencia relacional como asignatura pendiente a menudo del discurso pedagógico, y el Proceso del emana inexorablemente como relación educativa, porque se hace precisamente en ese caminar y escuchar(nos).

Finalmente, una Pedagogía de la Invitación a través de la cual seamos capaces de ver al otro desde su propia alteridad y desde la que obremos a partir de aspiraciones de convivencia y justicia social, más si cabe en relación al mundo educativo. Aquí las disyuntivas más implicadas serían la de Confianza-Respeto y la de SinguralidadColectividad, puesto que en ambas residen los pilares que vertebran la convivencia y que pueden permitir adjetivarla como educativa, desgranando las mismas desde las categoría siguientes: el Encuentro como elemento imprescindible para construir relaciones que no se encorseten en el utilitarismo y las diferencias transformadas en desigualdades, el Diálogo intercultural como apuesta ética en las educación, la Acción como forma de dar validez al discurso, y la Promoción como principio educativo desde el cual debe quedar patente que el sentido último de toda esta urdimbre se encuentra en la invitación permanente que la relación educativa para el crecimiento del otro-a y la reciprocidad que se da desde la misma. 


\section{A MOdo de CONCLUSIón}

Como hemos visto, las cuestiones educativas aquí reflejadas y las reflexiones éticas que hemos ido apuntando someramente, nos pueden dar la posibilidad de ir estableciendo una base para entender la relación educativa en base a las reflexiones e implicaciones emergentes desde las disyuntivas y tensiones planteadas y de su aplicación relacionada con los principios de una pedagogía de la alteridad. En esta línea, también es necesario destacar el papel crucial de este tema para la puesta en práctica del propio derecho a la educación. Siguiendo lo anteriormente expuesto se puede inferir el carácter ineludible para la construcción del derecho a la educación de relaciones verdaderamente educativas, ya que cercenar las mismas supone negar de alguna forma las dimensiones y categorías anteriormente definidas y desequilibrar las tensiones planteadas.

Y es que este posicionamiento teórico nos debe permitir también reconocer el papel fundamental que tenemos como educadores y educadoras respecto no sólo al reconocimiento del otro sino también desde las competencias que les atribuyamos y las expectativas que tengamos para con él o ella y su proceso de aprendizaje, de manera que podamos equilibrar, o al menos manejarnos, en las tensiones que nos indican los límites entre ser o no Frankenstein en nuestra docencia, o bien elevando a categoría de consciencia de orden ético la manera, cuantitativa y cualitativamente, en que podemos llegar a serlo. En función de variables como ésas, vinculadas a los procesos de sensibilidad, escucha e invitación pedagógica antes apuntados, hay que fomentar el modo de responder pedagógicamente al otro-a desde la forma en la que articulamos nuestra relación con él o ella.

\section{REFERENCIAS BIBLIOGRÁFICAS}

Asensio, J.M. (2010). El desarrollo del tacto pedagógico. Barcelona: Graó.

Augé, M. (1996). El sentido de los otros. Barcelona: Paidós.

Barba, P. (2002). Pedagogía y relación educativa. México: UNAM.

Bárcena, F. (2005). La experiencia reflexiva en educación. Barcelona: Paidós.

Bárcena, F. y Mélich, J. (2000). La educación como acontecimiento ético. Barcelona: Paidós.

Esteve, J.M. (2009). La urdimbre de la relación educativa. Oviedo: XXVIII Seminario Interuniversitario de Teoría de la Educación.

Esteve, J.M. (2010). Educar: un compromiso con la memoria. Barcelona: Octaedro.

Freire, P. (2006). Pedagogía de la autonomía. Madrid: Siglo XXI.

Gil Cantero, F. (2018). Escenarios y razones del antipedagogismo actual. Teoría de la Educación. Revista Interuniversitaria, 30(1), 29-51.

Habermas, J. (1987). Teoría de la Acción Comunicativa. Vols. I y II. Madrid: Taurus.

Jover, G. (1991). Relación educativa y relaciones humanas. Barcelona: Herder.

Jover, G. (2013). Teoría de la Educación. Manual para maestros, pedagogos y educadores sociales. Madrid: Universidad Complutense. Dpto. Teoría e Historia de la Educación. 
Lévinas, E. (1987). Totalidad e infinito. Salamanca: Sígueme.

Lévinas, E. (1991). Ética e infinito. Madrid: Visor.

Martínez, M., Esteban, F., Jover, G., y Payá, M. (2016). La educación en teoría. Madrid: Síntesis. Maturana, H. (1994). El sentido de lo humano. Santiago de Chile: Dolmen.

Maturana, H. y Nisis, S. (1997). Formación humana y capacitación. Santiago de Chile: Dolmen. Meirieu, Ph. (1998). Frankenstein educador. Barcelona: Laertes.

Meirieu, Ph. (2004). En la escuela hoy. Barcelona: Octaedro.

Molina, M ${ }^{a}$ D., Blanco, N. y Arbiol, C. (2016). Dejarse tocar para que algo nos suceda. En J. Contreras (Comp.), Tensiones fructíferas. Explorando el saber pedagógico en la formación del profesorado: una mirada desde la experiencia (pp. 111-150). Barcelona: Octaedro.

Nassif, R. (1980). Teoría de la educación. Problemática pedagógica contemporánea. Madrid: Cincel-Kapelusz.

Noddings, N. (2001). Care and coercion in school reform. Journal of Educational Change, 2, 35-43. https://doi.org/10.1023/A:1011514928048

Ortega, P. (2004). La educación moral como pedagogía de la alteridad. Bordón, 227, 5-30.

Ortega, P. (2016). La ética de la compasión en la pedagogía de la alteridad. Revista Española de Pedagogía, 264, 243-264.

Pallarés, M. y Chiva, O. (2017). La pedagogía de la presencia: tecnologías digitales y aprendizaje-servicio. Barcelona: UOC.

Postic, M. (2000). La relación educativa. Factores institucionales, sociológicos y culturales. Madrid: Narcea.

Prats, E. y Vilafranca, I. (2010). Teorías de la Educación. Barcelona: UOC.

Prieto, M. (2011). La Relación educativa como ejercicio de distancia: Una mirada a la experiencia compasiva desde Rousseau. Bajo Palabra. Revista de Filosofía, 6, 135-144.

Romero, C., Bernal, A. y Jiménez, J.R. (2009). Tejiendo vínculos: la textura de la relación educativa. En J.V. Peña y C. Ma Fernández (Coords.), La escuela en crisis (pp. 105-150). Barcelona: Octaedro.

Sidorkin, A.M. (2007). Las relaciones educativas. Barcelona: Octaedro.

Van Manen, M. (1998). El tacto en la enseñanza. El significado de la sensibilidad pedagógica. Barcelona: Paidós.

Van Manen, M. (2004). El tono en la enseñanza. Barcelona: Paidós.

Vila, E.S. (2006). Una voz que siente, un cuerpo que escucha, una mirada que invita: reflexiones éticas para una pedagogía de la alteridad. Bordón, 58 (1), 77-86.

Vila, E.S. (2012). Un juego de espejos: pensar la diferencia desde la pedagogía intercultural. Educación XX1, 15(2), 119-135. https://doi.org/10.5944/educxx1.15.2.129

VV.AA. (1981). La pedagogía Freinet por quienes la practican. Barcelona: Laia. 